\title{
INTERNATIONAL INTEGRATION ORGANIZATIONS AND THE SOVEREIGNTY OF MEMBER STATES
}

\author{
Dmitry V. Galushko \\ Financial University under the Government of the Russian Federation, Moscow, Russian Federation
}

Introduction: the paper analyzes the characteristics which are typical for the international integration organizations, generalized both at the doctrinal and normative levels, touches on the phenomenon of supranationality as a modern legal reality of international integration, and considers the basis for the transfer of sovereign powers by states, as the only bearers of sovereignty, to the international integration organizations. The purpose of the research is to study and analyze some aspects of the interaction between the international integration organizations and member states in the context of the supranational characteristics of such organizations. Methods: as part of the study, both the general scientific methods of cognition and the private legal methods (formal-legal, comparativelegal) were used. Results: the paper proves that the international integration organizations are a new reality of the modern system of international relations and international law. The author has established that such organizations have a number of characteristic features that distinguish them from the classical international intergovernmental organizations. As one of these main features, the author analyzes the phenomenon of supranationality, which is largely due to the voluntary transfer of their sovereign powers by the member states in favor of the integration associations. Conclusions: in contrast to the participation of states in the international organizations, the membership in the integration associations leads to the restriction of their sovereign rights by states, some of which are transferred to such an association. At the same time, such a transfer cannot be interpreted as their loss or the loss of their sovereign identity, because it's the state who is the bearer of sovereignty. We are talking about the voluntary transfer of certain sovereign powers that can be revoked at any time, which can be seen in the example of the process of Britain's exit from the European Union - Brexit.

Key words: integration, international organizations, membership in international organizations, European Union, sovereignty, delegation, Brexit.

Citation. Galushko D.V. International Integration Organizations and the Sovereignty of Member States. Legal Concept $=$ Pravovaya paradigma, 2021, vol. 20, no. 1, pp. 137-143. (in Russian). DOI: https: //doi.org/10.15688/lc.jvolsu.2021.1.21

УДК $341.1 / 8$

ББК 67.9
Дата поступления статьи: 12.01.2021

Дата принятия статьи: 31.01.2021

\section{МЕЖДУНАРОДНЫЕ ИНТЕГРАЦИОННЫЕ ОРГАНИЗАЦИИ И СУВЕРЕНИТЕТ ГОСУДАРСТВ-ЧЛЕНОВ}

\author{
Дмитрий Вячеславович Галушко \\ Финансовый университет при Правительстве Российской Федерации (Финуниверситет), г. Москва, \\ Российская Федерация
}


Введение: в статье анализируются типичные для международных интеграционных организаций признаки, обобщенные как на доктринальном, так и нормативном уровнях, затрагивается феномен наднациональности как современной правовой реальности международной интеграции, рассматриваются основы передачи суверенных полномочий государствами, как единственными носителями суверенитета, международным интеграционным организациям. Цель исследования заключается в исследовании и анализе некоторых аспектов взаимодействия международных интеграционных организаций и государств-членов в контексте наднациональных признаков таких организаций. Методы: в ходе исследования использовались как общенаучные методы познания, так и частноправовые методы (формально-юридический, сравнительно-правовой). Результаты: в статье обосновано, что международные интеграционные организации являются новой реальностью современной системы международных отношений и международного права. Автором установлено, что такие организации имеют ряд характерных черт, которые отличают их от классических международных межправительственных организаций. В качестве одной из таких главных черт анализируется феномен наднациональности, который во многом обусловлен добровольной передачей государствами-членами своих суверенных полномочий в пользу интеграционных объединений. Выводы: в отличие от участия государств в международных организациях, членство в интеграционных объединениях приводит к ограничению государствами своих суверенных прав, часть из которых передаются такому объединению. При этом подобная передача не может трактоваться как их потеря или потеря своей суверенной идентификации, ведь только государство является носителем суверенитета. Речь идет о добровольной передаче определенных суверенных полномочий, которые могут быть в любой момент отозваны, что можно наблюдать на примере процесса выхода Великобритании из Европейского Союза - Брекзита.

Ключевые слова: интеграция, международные организации, членство в международных организациях, Европейский Союз, суверенитет, делегирование, Брекзит.

Цитирование. Галушко Д. В. Международные интеграционные организации и суверенитет государств-членов // Legal Concept = Правовая парадигма. - 2021. - Т. 20, № 1. - C. 137-143. - DOI: https: //doi.org/10.15688/lc.jvolsu.2021.1.21

\section{Введение}

Новые условия обусловливают необходимость большего соответствия международноправового регулирования потребностям международного сообщества. Отставание международного права и его системы от развития международных отношений связано также с дроблением международного права на отрасли и возникновение автономных (специальных) режимов [4]. Тем не менее в международном праве уже произошли некоторые изменения, которые во многом являются отражением изменений в международных отношениях, связанных прежде всего с такими проявлениями, как интеграционные тенденции, а следовательно, наднациональность [11], передача суверенных полномочий и формирование интеграционных правопорядков [6]. Причем эти изменения касаются и такой очень консервативной и фундаментальной категории международного права, как его субъектный состав: под воздействием интеграции и появившейся в связи с этим концепции наднациональности [7] возникают новые международные институциональные формы - международные интеграционные организации, такие, прежде всего, как Европейский Союз, которые все более утверждают себя как особый участник международных экономических отношений, и это требует от исследователей дополнительных усилий по изучению правовых механизмов их функционирования [3], а некоторые ученые уже относят их в отдельную категорию субъектов международного права [1].

\section{Юридические признаки международных интеграционных организаций}

До сих пор не выделяется четких критериев для различия «традиционных» (или, иначе, «межправительственных») и «интеграционных» международных организаций. Во-первых, существует проблема определения «традиционной» международной организации. Это становится еще более сложным, потому что они имеют много общих черт, таких как учреждение на основе согласия, правосубъектность, отличная от государств-членов, независимых органов, собственных ресурсов и т. д. [22]. Межправительственные организа- 
ции характеризовались как организации, членами которых являются в основном, но не исключительно, национальные государства. Наднациональные организации также основаны преимущественно на членстве национальных государств, но такие организации имеют возможность принимать решения, которые автоматически становятся обязательными для их членов [20, p. 199].

Конструктивно можно выделить следующие отличия. «Наиболее фундаментальными характеристиками “традиционных” межправительственных организаций являются, вопервых, фактическая принадлежность полномочий по принятию решений представителям правительств государств-членов, а во-вторых, по важным вопросам на правительства не могут быть наложены обязательства против их воли» [8]. Межправительственные организации стремятся к сотрудничеству между правительствами и никоим образом не превосходят их $[13$, р. 55]. В свою очередь, наднациональная организация характеризуется следующими чертами: организация должна иметь полномочия принимать решения, обязательные для исполнения государствами-членами; институты, принимающие решения, не должны полностью зависеть от сотрудничества всех государств-членов; организация должна иметь право устанавливать правила, которые напрямую обязывают граждан государствчленов; организация должна иметь право исполнять свои решения; организация должна иметь некоторую финансовую автономию; односторонний выход из организации невозможен [13, р. 56-57].

Некоторые ученые указывают, что классический «межправительственный» подход характеризуется сохранением и осуществлением государствами-членами своей автономной суверенной власти в соответствии с правом, установлением совместной политики или принятием совместных решений при добровольном сотрудничестве в продвижении общих целей. Когда суверенные государства добровольно сотрудничают для достижения рыночной интеграции и других общих целей, то это часто называют «либеральным межправительственным подходом», основываясь на анализе, представленном в 1993 году известным ученым Андре Моравчиком [21].
В то же время термин «наднациональный» используется для характеристики централизованных и централизирующихся черт институциональной системы, прежде всего, ЕС. Как отмечается, Европейский Союз наверняка никогда не станет национальным государством и входящие в его состав государства-члены обязательно сохранят большинство своих суверенных характеристик, при этом вполне обоснованно можно называть ЕС наднациональной правовой структурой sui generis $[16$, p. 82]. Этого же мнения придерживается бывший судья Суда ЕС Коэн Ленертс, который также заключает, что термин «наднациональный» наиболее точно характеризует ЕС благодаря нескольким важным признакам: наличие институтов, независимых по составу и работе; использование процедур принятия решений большинством голосов, которые, тем не менее, являются обязательными для всех государств-членов; выполнение принятых решений учреждениями ЕС или под их контролем; создание в соответствии с договорами и подзаконными актами прав и обязанностей, обеспеченных возможностью применения принудительных мер [18].

Некоторые исследователи считают, что различие между двумя видами международных организаций следует проводить в соответствии с функциональным основанием. Утверждается, что «организации, чьей функцией является сотрудничество, соответственно, оставляют нетронутой базовую структуру современного международного сообщества, состоящего из суверенных государств», в то время как «организации, чьей функцией является интеграция, несут ответственность за сближение своих государств-членов, беря на себя некоторые из их функций, вплоть до слияния их в единое целое в секторе, в котором они осуществляют свою деятельность, то есть в сфере их компетенции» [5]. Одновременно с этим определенные важные функции государств (например, законодательная) будут выполняться органами такой организации от имени органов государств и от их имени [12, p. 55].

По мнению профессора Т.Н. Нешатаевой, характерной чертой наднациональных организаций является передача им государствами-членами суверенных функций: а) по 
управлению не только экономическими отношениями государств-членов, но и межхозяйственными связями физических и юридических лиц, имеющих гражданство этих государств-членов или действующих на их территории; б) по осуществлению международного взаимодействия с другими участниками международных экономических отношений, имея в виду, что суверенитет - верховенство власти внутри страны и ее независимость на внешней арене. Делается вывод, что наднационализм в широком смысле - это добровольное ограничение суверенной компетенции государственной власти. В основе такого ограничения - экономически обоснованный прагматизм, направленный на объединение хозяйственных ресурсов ради прогресса и развития [9].

Еще в 1982 году Джозеф Вейлер выделил две грани наднациональности: нормативную и в отношении принятия решений (цит. по: [10]). Состав обоих этих терминов может включать факторы, которые могут быть сформулированы на достаточном уровне обобщения, чтобы служить критериями для оценки прогресса или регресса двух конкретных аспектов наднациональности [24, p. 51].

На примере Европейского Союза профессор Кембаев выделяет следующие четыре критерия наднациональности. Во-первых, передача суверенных полномочий и, следовательно, возможность принимать решения, обязательные для государств-членов. Вовторых, принятие таких решений не полностью зависит от сотрудничества государствчленов. Таким образом, решения принимаются взвешенным большинством голосов и независимыми лицами в учреждениях. В-третьих, верховенство и прямое действие права ЕС и способность обеспечивать его соблюдение. В-четвертых, финансовая автономия [17, p. 15-16].

\section{Передача суверенных полномочий государств международным интеграционным организациям}

Суверенитет все еще остается в современном международно-правовом регулировании важнейшим элементом правовой реальности и фактически юридическим символом государства, а современное международное право не содержит норм, запрещающих государствам ограничивать свой суверенитет на добровольных началах, тем не менее, объем и характер такого ограничения является весьма дискуссионным [2]. Как отмечается в современной доктрине, ключевыми вопросами в современном международно-правом дискурсе являются способ наделения международной организации полномочиями, а также объем и вид тех полномочий, которыми государства наделяют такую международную организацию [15].

Д. Саароши отмечает, что в современной доктрине и в практике международных организаций:

во-первых, используется разная терминология для раскрытия содержания правовых отношений, возникающих между государствами как основными субъектами современного международного права и международными организациями в момент создания, например, цессия полномочий (ceding of powers), отчуждение полномочий (alienation of powers), трансфер полномочий (transfer of powers), делегирование полномочий (delegation of powers), передача суверенитета (conferral of sovereignty) и т. д.;

во-вторых, хотя эти термины употребляются взаимозаменяемо, они фактически определяют разный уровень наделения международной организации компетенцией и в значительной степени зависят от объема и содержания тех полномочий, которые государства-члены предоставляют международной организации;

в-третьих, разнообразие отношений по наделению международной организации полномочиями колеблется от отношений представительства или поручения (agency relationship) через институт делегирования полномочий от государств к международной организации и допередачи полномочий международной организации, причем вид и объем полномочий, которыми наделяется международная организация, могут быть весьма различными;

в-четвертых, наиболее общим термином, который охватывает все правовые отношения, возникающие между международной организацией игосударствами, которые ее создают, является «передача полномочий» (conferral of powers) [23]. 
Под делегированием в публичном праве понимают правовой акт, в результате которого носитель полномочий государства, следовательно, само государство или один из его органов переносят собственную компетенцию полностью или определенную ее часть на другие субъекты [14]. В частности, в деле Meroni четко сформулировано положение о запрете презумпции делегирования полномочий: «Делегирование полномочий нельзя презюмировать. Даже если уполномоченный делегировать должен принять решение о делегировании полномочий» [19].

Юридическим признаком передачи полномочий является предоставление суверенных прав международной организации, при этом они автоматически не изымаются из предметной области регулирования государства-члена, более того, адресатом переданных полномочий выступает международная организация.

\section{Выводы}

В заключение следует отметить, что членство государства в международных интеграционных организациях неразрывно связано с вопросом реализации государством своего суверенитета на международной арене. Передача суверенных полномочий государства было и остается необходимым условием его участия в формировании международных интеграционных организаций. В контексте участия государств в международных интеграционных процессах реализация государственного суверенитета как во внешнеполитическом, так и внутренне-правовом измерениях обусловлена необходимостью достижения их общих интеграционных целей, что, в свою очередь, обусловливает зависимость объема компетенции международных интеграционных организаций от воли государств, которая, с другой стороны, на современном этапе развития международных отношений выходит за рамки национальных границ и интересов. Тем самым, членство в международной интеграционной организации может уменьшить объем суверенных полномочий государства на основе механизма их делегирования, однако, их отзыв, как, впрочем, и решение перестать быть частью такого интеграционно- го объединения, по-прежнему находится в суверенной власти соответствующего государства, что, между прочим, можно проследить на примере процесса выхода Великобритании из Европейского Союза - Брекзита.

\section{СПИСОК ЛИТЕРАТУРЫ}

1. Бекяшев, К. А. ЕАЭС: международная (межгосударственная) организация или международное (межгосударственное) интеграционное объединение? / К. А. Бекяшев // Евразийский юридический журнал. - 2014. - № 11. - С. 14-16.

2. Бирюков, М. М. Европейское право до и после Лиссабонского договора / М. М. Бирюков. М. : Научная книга, 2010.

3. Волова, Л. И. Правовой статус региональных интеграционных объединений / Л. И. Волова // Российский ежегодник международного права 2012. - СПб., 2013. - С. 96-107.

4. Кислицына, Н. Ф. Развитие системы международного права на современном этапе : автореф. дис. ... канд. юрид. наук / Кислицына Наталия Феликсовна. - М., 2010.

5. Михалева, Т. Н. Правовые основания создания и функционирования межгосударственных интеграционных объединений / Т. Н. Михалева // Право и государство. - 2018. - № 3-4. - С. 90-101.

6. Моисеев, А. А. Соотношение суверенитета и надгосударственности в современном международном праве : в контексте глобализации : автореф. дис. ... д-ра юрид. наук / Моисеев Алексей Александрович. - М., 2007.

7. Моисеев, А. А. Надгосударственность в международном праве / А. А. Моисеев // Государство и право. -2007 . - № 8. - С. 67-73.

8. Мысливский, П. П. Признаки и определение понятия «Наднациональная международная организация» / П. П. Мысливский // Гуманитарные, социально-экономические и общественные науки. - 2015. - № 6-1. - С. 364-367.

9. Нешатаева, Т. Н. Интеграция и наднационализм / Т. Н. Нешатаева // Российское правосудие. -2014 . -№ 9. - С. 243-248.

10. Стрежнева, М. В. Наднациональность и принцип субсидиарности в ЕС и за его пределами / М. В. Стрежнева // Мировая экономика и международные отношения. -2016 . - Т. 60, № 6. - С. 5-14.

11. Шпакович, О. Н. Наднациональность в праве международных организаций / О. Н. Шпакович // Вестник международных организаций. - 2012. № 2. - C. 133-143.

12. Abi-Saab, G. The Concept of International Organization / G. Abi-Saab. - Paris : UNESCO, 1981. 
13. Blokker, N. M. International Institutional Law: Unity Within Diversity, Fifth Revised Edition / N. M. Blokker, H. G. Schermers. - Leiden : BRILL, 2011.

14. Bradley, C. A. The Concept of International Delegation / C. A. Bradley, J. G. Kelley // Law and Contemporary Problems. - 2008. - № 71. - P. 1-36.

15. Erne, J. Conferral of Powers by States as a Basis of Obligation of International Organisations / J. Erne// Nordic Journal of International Law. - 2009. Vol. 78, Iss. 2. - P. 177-199. - DOI: https://doi.org/ $10.1163 / 157181009 X 431749$.

16. Goebel, R. J. Supranational? Federal? Intergovernmental? The Governmental Structure of the European Union After the Treaty of Lisbon / R. J. Goebel // Columbia Journal of European Law. 2013. - № 20. - P. 77-142.

17. Kembayev Z. Legal Aspects of the Regional Integration Processes in the Post-Soviet Area / Z. Kembayev. - Berlin; Heidelberg: Springer, 2010.

18. Lenaerts, K. Constitutional Law of the European Union / K. Lenaerts, P. Van Nuffel, R. Bray.London : Sweet \& Maxwell, 2010.

19. Merone \& Co., Industrie Metallurgische, SpA $\mathrm{v}$ High Authority of the European Coal and Steel Community: Judgment of the Court of 13 June 1958 Case 9-56. - English special edition, 1957-1958, 00133.

20. Miles, E. Organizations and Integration in International Systems / E. Miles // International Studies Quarterly. - 1968. - Vol. 12, № 2,- P. 196-224.

21. Moravcsik, A. Preferences and Power in the European Community: A Liberal Intergovernmentalist Approach / A. Moravesik // JCMS: Journal of Common Market Studies. - 1993. - № 31 - - P. 473-524. - DOI: https://doi.org/10.1111/j.1468-5965.1993.tb00477.x14.

22. Rosenberg, A. International Interaction: A Preliminary Proposed Taxonomy of International Organizations / A. Rosenberg // International Associations. - 1967. - № 11. - P. 721-730.

23. Sarooshi, D. Some Preliminary Remarks on the Conferral by States of Powers on International Organizations / D. Sarooshi. - New York : New York University School of Law, 2003.

24. Weiler, Joseph H. H. Supranational Law and the Supranational System : Legal Structure and Political Process in the European Community / Joseph H. H. Weiler. - Florence : European University Institute, 1982.

\section{REFERENCES}

1. Bekjashev K.A. EAJeS: mezhdunarodnaya (mezhgosudarstvennaya) organizatsiya ili mezhdunarodnoe (mezhgosudarstvennoe) integracionnoe obedinenie? [EAEU: International (Interstate) Organization or International (Interstate) Integration Entity]. Evrazijskij yuridicheskij zhurnal [Eurasian Law Journal], 2014, no. 11, pp. 14-16.

2. Birjukov M.M. Evropejskoe pravo do i posle Lissabonskogo dogovora [European Law Before and After the Lisbon Treaty]. Moscow, Nauchnaya kniga Publ., 2010.

3. Volova L.I. Pravovoj status regionalnykh integratsionnykh obedinenij. Rossijskij ezhegodnik mezhdunarodnogo prava 2012 [Russian Yearbook of International Law], Saint Petersburg, 2013, pp. 96-107.

4. Kislicyna N.F. Razvitie sistemy mezhdunarodnogo prava na sovremennom etape: avtoref. dis. ... kand. yurid. nauk [Development of the System of International Law at the Present Stage. Cand. yurid. sci. diss.]. Moscow, 2010.

5. Mihaleva T.N. Pravovye osnovaniya sozdaniya i funktsyonirovaniya mezhgosudarstvennykh integratsyonnykh obedinenij [Legal Grounds for the Creation and Functioning of Interstate Integration Associations].Pravo i gosudarstvo [Law and State], 2018, no. 3-4, pp. 90-101.

6. Moiseev A.A. Sootnoshenie suvereniteta $i$ nadgosudarstvennosti $v \quad$ sovremennom mezhdunarodnom prave: $v$ kontekste globalizatsyi: avtoref. dis. ... d-ra yurid. nauk [The Ratio of Sovereignty and Supranationality in Modern International Law: in the Context of Globalization: Doc. jurid. sci. diss.]. Moscow, 2007.

7. Moiseev A.A. Nadgosudarstvennost v mezhdunarodnom prave [Supranationality in International Law]. Gosudarstvo i pravo [Law and State], 2007, no. 8, pp. 67-73.

8. Myslivskij P.P. Priznaki i opredelenie ponyatiya «Nadnatsyonalnaya mezhdunarodnaya organizatsyya» [Signs and Definition of the Concept of "Supranational International Organization"]. Gumanitarnye, sotsyalnoekonomicheskie $i$ obshchestvennye nauki [Humanitarian, Socio-economic, and Social Sciences], 2015, no. 6-1,pp. 364-367.

9. Neshataeva T.N. Integratsyya i nadnatsyonalizm [Integration and Supranationality]. Rossijskoe pravosudie [Russian Justice], 2014, no. 9 , pp. 243-248.

10. Strezhneva M.V. Nadnatsyonalnost i printsyp subsidiarnosti $v$ ES i za ego predelami [Supranationality and the Principle of Subsidiarity in the EU and Beyond]. Mirovaya ekonomika $i$ mezhdunarodnye otnosheniya [World Economy and International Relations], 2016, vol. 60, no. 6, pp. 5-14.

11. Shpakovich O. N. Nadnatsyionalnost v prave mezhdunarodnykh organizatsyj [Supranationality in the Law of International Organizations]. Vestnik mezhdunarodnykh organizatsyj [Herald of International Organizations], 2012, no. 2, pp. 133-143.

12. Abi-Saab G. The Concept of International Organization. Paris, UNESCO, 1981. 
13. Blokker N.M., Schermers H.G. International Institutional Law: Unity Within Diversity, Fifth Revised Edition. Leiden, BRILL, 2011.

14. Bradley C.A., Kelley J.G. The Concept of International Delegation. Law and Contemporary Problems, 2008, no. 71, pp. 1-36.

15. Erne J. Conferral of Powers by States as a Basis of Obligation of International Organisations. Nordic Journal of International Law, 2009, vol. 78, iss. 2, pp. 177-199. DOI: https://doi.org/10.1163/ 157181009 X431749.

16. Goebel R.J. Supranational? Federal? Intergovernmental? The Governmental Structure of the European Union After the Treaty of Lisbon. Columbia Journal of European Law, 2013, no. 20, pp. 77-142.

17. Kembayev Z. Legal Aspects of the Regional Integration Processes in the Post-Soviet Area. Berlin; Heidelberg, Springer, 2010.

18. Lenaerts K., Nuffel P. Van, Bray R. Constitutional Law of the European Union. London, Sweet \& Maxwell, 2010.

19. Merone \& Co., Industrie Metallurgische, $S p A v$ High Authority of the European Coal and
Steel Community: Judgment of the Court of 13 June 1958 - Case 9-56. English special edition, 1957-1958, 00133.

20. Miles E. Organizations and Integration in International Systems. International Studies Quarterly, 1968, vol. 12, no. 2, pp. 196-224.

21. Moravcsik A. Preferences and Power in the European Community: A Liberal Intergovernmentalist Approach. JCMS: Journal of Common Market Studies, 1993, no. 31, pp. 473-524. DOI: https://doi.org/ 10.1111/j.1468-5965.1993.tb00477.x14.

22. Rosenberg A. International Interaction: A Preliminary Proposed Taxonomy of International Organizations. International Associations, 1967, no. 11 , pp. $721-730$.

23. Sarooshi D. Some Preliminary Remarks on the Conferral by States of Powers on International Organizations. New York, New York University School of Law, 2003.

24. Weiler Joseph H.H. Supranational Law and the Supranational System: Legal Structure and Political Process in the European Community. Florence, European University Institute, 1982.

\section{Information About the Author}

Dmitry V. Galushko, Candidate of Sciences (Jurisprudence), Associate Professor, Department of Legal Regulation of Economic Operations, Financial University under the Government of the Russian Federation, Leningradskiy Prosp., 49, 125993 Moscow, Russian Federation, galushkodv@gmail.com, https://orcid.org/0000-0002-9301-9565

\section{Информация об авторе}

Дмитрий Вячеславович Галушко, кандидат юридических наук, доцент, доцент Департамента правового регулирования экономической деятельности, Финансовый университет при Правительстве Российской Федерации (Финуниверситет), Ленинградский просп., 49, 125993 г. Москва, Российская Федерация, galushkodv@gmail.com, https://orcid.org/0000-0002-9301-9565 